\title{
Prevention of primary non-function of islet xenografts in autoimmune diabetic NOD mice by anti-inflammatory agents
}

\author{
C. Gysemans ${ }^{1}$, K. Stoffels ${ }^{1}$, A. Giulietti ${ }^{1}$, L. Overbergh ${ }^{1}$, M. Waer ${ }^{2}$, M. Lannoo ${ }^{3}$, U. Feige ${ }^{4}$, C. Mathieu ${ }^{1}$ \\ ${ }^{1}$ LEGENDO, UZ Gasthuisberg O\&N, Leuven, Belgium \\ 2 Laboratory for Experimental Transplantation, Catholic University of Leuven, UZ Gasthuisberg, Leuven, Belgium \\ ${ }^{3}$ Department of Surgery, UZ Gasthuisberg, Leuven, Belgium \\ ${ }^{4}$ Amgen Center, Thousand Oaks, California, USA
}

\section{Abstract}

Aims/hypothesis. High levels of inflammation locally in the graft during the initial days after transplantation can cause primary non-function (PNF) of grafted xenogeneic islets in NOD mice. The aim of this study was to explore in a model of spontaneous diabetes, the NOD mouse, the potential of anti-inflammatory agents in the prevention of PNF after xenogeneic islet transplantation.

Methods. Spontaneously diabetic NOD mice were transplanted with 300 rat islets. Animals were treated with acetylsalicylic acid (AsA), rofecoxib, TGF- $\beta$ or IL-1 receptor antagonist (IL-1ra). Intra-graft expression of inflammation-related molecules was measured by real time PCR $8 \mathrm{~h}$ post-transplantation. At the same time point, plasma nitrite levels were measured.

Results. Xenogeneic islets transplanted in control spontaneously diabetic mice resulted in PNF in 16 out of 38 mice $(42 \%)$. Initial graft loss was not altered by administration of rofecoxib (30\%) or TGF- $\beta$ (25\%).
AsA reduced the rate of rapid graft loss to $8 \%(p<0.05$ vs controls) and administration of IL-1ra even totally prevented PNF ( $0 \%, p<0.05$ vs controls). Furthermore, all therapies prolonged the mean survival time of xenogeneic islet grafts. The inhibition of PNF by AsA was associated with decreased intra-islet levels of inflammation-related molecules (IL-1, TNF- $\alpha$, iNOS, COX-2) and chemokines (MCP-1 and MIP$3 \alpha$ ). Finally, also a diminished production of systemic nitrite levels was observed in AsA- and IL-1ra-treated islet recipients.

Conclusions/Interpretation. These data show that treatment with AsA or IL-1ra prevents PNF after islet transplantation in spontaneously diabetic NOD mice. Moreover, the involvement of non-specific inflammation is recognized in xenogeneic islet PNF in spontaneously diabetic NOD mice. [Diabetologia (2003) 46:1115-1123]

Keywords Primary non-function, islets, NOD mice, inflammatory cytokines, nitric oxide.
Received: 3 February 2003 / Revised: 1 April 2003

Published online: 17 July 2003

C) Springer-Verlag 2003

Corresponding author: Dr. C. Mathieu, LEGENDO, UZ Gasthuisberg O\&N, Herestraat 49, 3000 Leuven, Belgium

E-mail: chantal.mathieu@med.kuleuven.ac.be

Abbreviations: AsA, acetylsalicylic acid; COX, cyclo-oxygenase; iNOS, inducible nitric oxide synthase; IP-10, interferon- $\gamma$ inducible protein-10; MCP-1, monocyte chemo-attractant protein-1; MIP-3 $\alpha$, macrophage inflammatory protein-3 $\alpha$; NO, nitric oxide; NOD mice, non-obese-diabetic mice; PG, prostaglandin; PNF, primary non-function.
Pancreatic islet cell transplantation is proposed as an ideal future treatment option for patients with Type 1 diabetes, allowing stable glucose homeostasis without exogenous insulin regimens and thus avoiding the risk of developing life-threatening diabetic complications $[1,2]$. Despite the recent success rate of $80 \%$ of patients not requiring insulin for one year following islet transplantation $[3,4]$, scarce availability of human organs for islet cell isolation and the chronic necessity for strong immunosuppressive agents to overcome islet cell graft destruction, limit the introduction of islet transplantation into the clinical practice [5].

An appealing solution for the limited availability of human islet material is the use of xenogeneic islets, 
for example from pigs. Unfortunately, the nature of xenogeneic islet cell destruction remains poorly understood and in animal models, xenograft rejection seems to be more aggressive than islet allograft rejection [6]. It has been shown that massive infiltration by macrophages, NK cells and granulocytes, particularly eosinophils characterizes the xenograft response [7, 8].

We and others previously reported in the early posttransplant period that islet grafts and especially xenografts are subject to very aggressive inflammatory reactions by the recipient's immune system $[9,10,11]$. The excessive release of inflammation-related cytokines, such as interleukin (IL)-1 and tumour necrosis factor (TNF)- $\alpha$, might be the reason for the high rate of early graft failure (primary non-function, PNF) observed under these circumstances [11]. Especially islet grafts transplanted into autoimmune diabetic NOD mice seem to be subject to a high rate of early islet graft loss, suggesting a contribution of the autoimmune background to this phenomenon. Based on the timing of this phenomenon $(<24 \mathrm{~h})$, the absence of infiltrating $\mathrm{T}$ lymphocytes in the grafts at that moment and the profile of cytokines expressed locally in the non-functioning grafts (mainly IL-1 and TNF- $\alpha$ ) [11], it is clear that a major role in primary islet non-function is played by the non-T-cell immune system, especially activated macrophages. This point of view is supported by growing evidence supporting abnormalities of macrophages in both NOD mice [12, 13, 14] and in Type 1 diabetic patients $[15,16]$.

Classical immunosuppressive drugs however, are mainly T-lymphocyte-targeted and are unable to prevent the early islet graft destruction $[17,18,19]$, unless they are combined with drugs that also interfere with the non-T-cell immune system such as analogues of vitamin D or leflunomide [18, 19].

The aim of this study was to investigate whether blocking of the local inflammatory reaction using non-steroidal anti-inflammatory drugs such as acetylsalicylic acid (AsA) or more specific regimens such as IL-1 receptor antagonist (IL-1ra) could prevent primary islet non-function and whether this intervention would influence global graft survival in an autoimmune setting of Type 1 diabetes (the NOD mouse).

\section{Materials and methods}

Animals. NOD mice were kindly provided by Prof. C.Y. Wu (Beijing, China) and were inbred in our animal facility since 1990. Housing of NOD mice occurred under semi-barrier conditions and animals received standard mouse chow and water ad libitum [20]. Female and male NOD mice were screened twice weekly for diabetes by measuring urine (Clinistix, Bayer Diagnostics, Tarrytown, N.Y., USA) and blood glucose (Glucocard, Menarini, Florence, Italy) levels after 70 days of age. At the time of the experiments, the diabetes incidence in our colony was $72 \%$ in female and $12 \%$ in male mice at the age of 200 days. Spontaneously diabetic NOD mice, defined as having positive glucosuria and hyperglycaemia (>200 mg/dl) on two consecutive days, were used within 7 days after diabetes diagnosis as autoimmune diabetic xenograft recipients.

Islet isolation and transplantation. Islets were isolated from Piebald Viral Glaxo (PVG) C6-sufficient rats $(<14$ days old; Rega-institute, Leuven, Belgium) by collagenase digestion of the pancreas [11]. Islets were separated on a dextran-density gradient and selected with a stereomicroscope to exclude any contaminating tissues. Islets were suspended in ice cold RPMI 1640 medium (Invitrogen Corporation/Life Techologies, Carlsbad, Calif., USA) supplemented with $10 \%$ foetal calf serum before transplantation. Recipient animals were anaesthetized with an intraperitioneal injection of avertin solution $(0.02 \mathrm{ml} / \mathrm{g}$ $\mathrm{BW}$ ), which is $25 \mathrm{~g} \mathrm{2-,2-,2-tribromoethanol} \mathrm{(Fluka,} \mathrm{Buchs,}$ Switzerland) dissolved into $15.5 \mathrm{ml}$ tertiary amyl alcohol (Fluka). The left kidney was exposed by a lumbar incision and recipient mice were given 300 fresh islets under the renal capsule by a drawn-out Pasteur pipette. All animal experimental procedures were approved and carried out in accordance with the Ethics Committee of the Catholic University of Leuven and following NIH guidelines [NIH publication no. 85-23, revised 1985].

Graft function. The non-fasting blood glucose levels from the tail vein of each recipient were measured daily during the first week post-transplantation and thereafter three times weekly to monitor the rate of primary non-function and islet graft rejection. Primary non-function was defined as blood glucose levels never reaching normoglycaemia $24 \mathrm{~h}$ after islet cell transplantation, while diabetes recurrence was defined as a return to hyperglycaemia ( $>200 \mathrm{mg} / \mathrm{dl}$ blood glucose) after a period of normal blood glucose levels. Mice were killed after confirmation of diabetes recurrence, and the transplanted kidneys were harvested for histology.

Treatment regimens. Acetylsalicylic acid (Sigma-Aldrich, Seelze, Germany) at a dose of $200 \mathrm{mg} / \mathrm{kg}$ was administered by oral gavage $(0.2 \mathrm{ml})$ as a fine suspension in $1 \%$ carboxymethylcellulose (CMC). Treatment was administered daily starting 1 day prior to transplantation for as long as mice were normoglycaemic.

Rofecoxib, a cyclo-oxygenase (COX)-2-selective inhibitor (Vioxx, Merck, Whitehouse Station, N.J., USA) was applicated in $1 \% \mathrm{CMC}$ by oral gavage in a dosage of $10 \mathrm{mg} / \mathrm{kg} /$ day starting one day prior to grafting for as long as mice were normoglycaemic.

Human recombinant transforming growth factor (TGF)- $\beta 1$ (R\&D Systems, Minneapolis, Minn., USA) was given intraperitoneally on day $-1,0$ and $4 \mathrm{~h}$ post-transplantation as a $0.2 \mathrm{ml}$ suspension in sterile phosphate buffered saline (PBS) $+0.2 \%$ bovine serum albumin (filter sterilized) to obtain a total dose of $30 \mu \mathrm{g} / \mathrm{kg} /$ day per recipient.

Human recombinant IL-1ra (Anakinra, kind gift of Dr. Feige, the Amgen Center, Thousand Oaks, Calif., USA) was intraperitoneally injected according to the manufacturer's instructions at a dose of $100 \mathrm{mg} / \mathrm{kg}$ on day -1 , day 0 and $4 \mathrm{~h}$ post-transplantation as a $0.2 \mathrm{ml}$ suspension in citrate buffered saline with ethylene diamine tetra-acetic acid and polysorbate. Alternatively, IL-1ra was delivered by an in vitro-primed osmotic pump (ALZET, Durect, Cupertino, Calif., USA; $100 \mathrm{mg} / \mathrm{kg} /$ day) from day -1 till day of return to hyperglycaemia. 
Real time RT-PCR of the grafts. Using the ABI Prism 7700 SDS (Applied Biosystems, Foster City, Calif., USA) in combination with TaqMan chemistry, real-time reverse transcriptasepolymerase chain reaction (RT-PCR) analysis of the islet grafts was carried out [21]. The primer sequences and probes for the murine genes were as follows: IL-1ra: F 5'-CTGGGAAAAGACCCTGCAAG-3', R 5'-CCAGCAATGAGCTGGTTCTTT-3', P 5'-TGCAAGCCTTCAGAATCTGGGATACTAACCA-3', COX-2: F 5'-TGGTGCCTGGTCTGATGATG-3', R 5'-GTGGTAACCGCTCAGGTGTTG-3', P 5'-CCACCATCTGGCTTCGGGAGCA-3', nuclear factor (NF)-кBp105: F 5'-AACAAAATGCCCCACGGTTA-3', R 5'-GGGACGATGCAATGGACTGT-3', P 5'-CCGTTCCCCCACACTGTGTAAACCA-3'. Primers and probes for IL- 1 , TNF- $\alpha$, TGF- $\beta$, inducible nitric oxide synthase (iNOS), monocyte chemo-attractant protein (MCP)-1, macrophage inflammatory protein (MIP)-3 $\alpha$, interferon- $\gamma$ inducible protein (IP)-10 and $\beta$-actin as housekeeping gene were as described [21, 22, 23]. In a separate experiment, mice were killed $8 \mathrm{~h}$ post-transplantation and isolated grafts as well as a small slice of un-manipulated kidney tissue were frozen in liquid nitrogen and stored at $-80^{\circ} \mathrm{C}$ until further analysis. TRIzol reagent (Invitrogen Corporation/Life Technologies) was used to extract total RNA as indicated by the manufacturer. Total RNA was reverse transcribed to cDNA by adding $5 \mu \mathrm{mol} / \mathrm{l}$ Oligo(dT) ${ }_{16}$ (Applied Biosystems) to $0.5 \mu \mathrm{g}$ of total RNA, which was heated to $72^{\circ} \mathrm{C}$ for $10 \mathrm{~min}$ and subsequently cooled on ice. Secondly, $100 \mathrm{U}$ of Superscript II reverse transcriptase (Invitrogen Corporation/Life Technologies) was added in the presence of $50 \mathrm{mmol} / \mathrm{l}$ Tris- $\mathrm{HCl} \mathrm{pH} \mathrm{8.3,} 75 \mathrm{mmol} / \mathrm{l} \mathrm{KCl}$, $3 \mathrm{mmol} / 1 \mathrm{MgCl}_{2}, 5 \mathrm{mmol} / \mathrm{l}$ DTT and $0.5 \mathrm{mmol} / \mathrm{l} \mathrm{dNTPs}$ and kept at $42^{\circ} \mathrm{C}$ for $80 \mathrm{~min}$. With the objective of acquiring a relative quantification of transcription, cDNA plasmid standards were constructed for each individual target. PCR amplifications were done in triplicate wells in a total volume of $25 \mu \mathrm{l}$, containing $0.5 \mu \mathrm{l}$ cDNA sample, $50 \mathrm{mmol} / \mathrm{l} \mathrm{KCl}, 10 \mathrm{mmol} / \mathrm{l}$ Tris- $\mathrm{HCl}$ ( $\mathrm{pH} 8.3$ ), $10 \mathrm{mmol} / \mathrm{l}$ EDTA, $60 \mathrm{nmol} / \mathrm{l}$ Passive Reference $1200 \mu \mathrm{mol} / \mathrm{l} \mathrm{dNTPs}, 3$ to $9 \mathrm{mmol} / \mathrm{l} \mathrm{MgCl}_{2}, 100$ to $900 \mathrm{nmol} / \mathrm{l}$ of each primer, $100 \mathrm{nmol} / \mathrm{l}$ of TaqMan probe and $0.625 \mathrm{U}$ AmpliTaqGold (AppliedBiosystems), using the following conditions: $10 \mathrm{~min}$ at $94^{\circ} \mathrm{C}$, followed by a total of 35 to 45 two-temperature cycles $\left(15 \mathrm{~s}\right.$ at $94^{\circ} \mathrm{C}$ and $1 \mathrm{~min}$ at $\left.60^{\circ} \mathrm{C}\right)$. We carried out for each sample a correction for reverse transcriptase variability by normalization to $\beta$-actin. mRNA levels were expressed as percentage of control values (the ratio between the copies of the gene of interest and the copies for $\beta$-actin).

Plasma nitrite measurement. Blood was drawn from the tail vein of islet graft recipients before and $8 \mathrm{~h}$ after islet transplantation. Nitrite production was determined in triplicate by mixing $50 \mu \mathrm{l}$ of undiluted blood plasma with $50 \mu \mathrm{l}$ of sulphanilamide solution and incubated for 5 to $10 \mathrm{~min}$ at room temperature, protected from sunlight. After incubation, $50 \mu \mathrm{l}$ of $\mathrm{N}-1$ napthylethylenediamine dihydrochloride solution was dispensed to all wells. The absorbance at $540 \mathrm{~nm}$ was determined after 5 to 10 minutes of incubation at room temperature, again under dark conditions (Promega Corporation, Madison, Wis., USA). Nitrite concentrations were calculated from a sodium nitrite standard curve.

Statistical analysis. All values were expressed as means \pm SEM. Statistical analysis was done by using NCSS Statistical Software (NCSS, Kaysville, Utah., USA). We used the Kaplan-Meier survival technique, the Log-Rank test, the Chi square test, the analysis of variance-to detect inter-group differences-followed by Bonferroni (versus control) MultipleComparison Test as appropriate. A $p$ value of less than 0.05 was considered statistically significant.

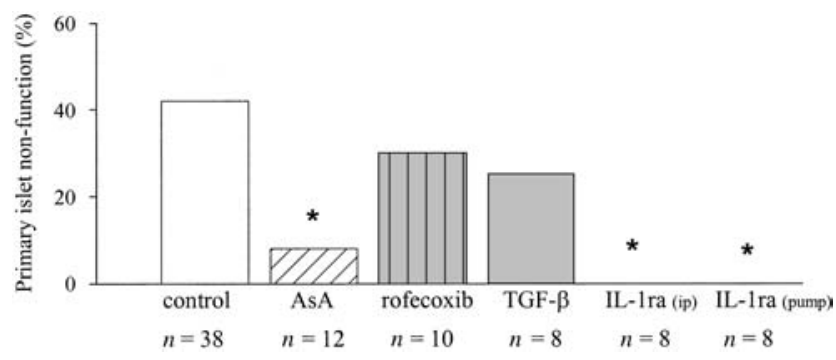

Fig. 1. Incidence of primary non-function after rat islet transplantation in autoimmune diabetic NOD mice. Treatments were initiated the day before transplantation and function was evaluated daily after transplantation. Primary non-function was defined as failure of the grafts to normalise glycaemia within 24 h. $* p<0.05$ compared to control mice

\section{Results}

Effect of anti-inflammatory agents on primary nonfunction after transplantation of xenogeneic islets in autoimmune diabetic NOD mice. In 16 out of 38 spontaneously diabetic NOD mice, plasma glucose values never returned to normal within $24 \mathrm{~h}$ after rat islet transplantation (42\% PNF) (Fig. 1), confirming our previous results. The mean graft survival (MST) in the recipients, which did not show PNF, was 6.2 \pm 4.4 days (Fig. 2).

PNF was not observed in most (11 out of 12) mice treated with high-dosed acetylsalicylic acid (8\% PNF, $p<0.05$ vs. controls) (Fig. 1). In addition, islet xenograft survival without PNF was improved compared to control animals (MST 10.0 \pm 5.1 days, $p<0.001$ ) (Fig. 2A) and was comparable to previous observations in alloxan-induced diabetic NOD mice. In the rofecoxib-treated group, three out of 10 islet recipients had failing graft function (30\% PNF, NS vs. controls) (Fig. 1), while functional graft survival was significantly prolonged compared to untreated controls (MST 10.5 \pm 6.0 days, $p<0.005$ ) (Fig. 2A). When recombinant TGF- $\beta$ was administered, no reduction in PNF was seen [25\% (2 out of 8), NS vs. controls] but again mean survival time without PNF was prolonged to $9.8 \pm 7.8$ days ( $p<0.01$ vs. controls) (Fig. 1, Fig. 2B). Complete lack of early graft failure ( 0 out of 8 and 0 out of $8, p<0.05$ vs. controls) was observed when antagonizing or modifying the action of pro-inflammatory IL-1 by treatment with IL-1ra (100 mg/kg/day, i.p. or pump, respectively). Mean graft survival without PNF was prolonged to $8.5 \pm 4.1$ days in i.p.-treated mice ( $p<0.05$ vs. controls) and $9.0 \pm 0.0$ days in pumptreated mice ( $p<0.01$ vs. controls) (Fig. $2 \mathrm{~B})$.

Intra-graft expression of inflammation-related genes. We previously showed that primary islet non-function in autoimmune diabetic NOD mice was associated with high intra-graft IL- 1 and low TGF- $\beta$ mRNA expression $8 \mathrm{~h}$ after transplantation. 


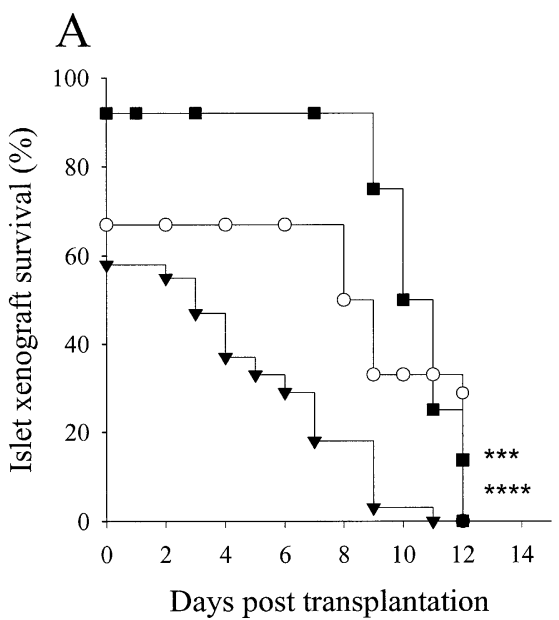

Fig. 2A, B. Effect of different treatment regimens on immediate islet xenograft survival in autoimmune diabetic NOD mice. Transplantation of rat islet cells in untreated autoimmune diabetic animals was used as a control $(\boldsymbol{\nabla})$. Panel (A) shows survival under acetylsalicylic acid (AsA) $(\boldsymbol{\square}, n=11)$ and rofecoxib $(\bigcirc, n=7)$ treatment. Panel (B) shows islet survival under TGF$\beta(\square, n=6)$ as well as under IL-1ra administration, either intraperitoneally $(\cap, n=8)$ or subcutaneously $(\nabla, n=8)$. ${ }^{*} p<0.05$, $* * p<0.01, * * * p<0.005, * * * * p<0.001$ compared to control mice

In order to study whether application of different treatment regimens had any effect on the balance between pro- and anti-inflammation-related gene transcription locally in the islet grafts, we analyzed islet grafts of a separate series of control mice and mice treated with acetylsalicylic acid, rofecoxib, TGF- $\beta$ and IL-1ra (pump) $8 \mathrm{~h}$ post-transplantation by real-time RT-PCR. Administration of acetylsalicylic acid was able to reduce the gene expression for all pro-inflammatory cytokines (IL-1 and TNF- $\alpha$ ) and enzymes (iNOS and COX-2) tested (Fig. 3). In addition, grafts of acetylsalicylic acid-treated mice had low mRNA expression for the chemokines MCP-1 and MIP- $3 \alpha$ compared to control grafts, while anti-inflammatory TGF- $\beta$ and IL-1ra were three- and four-fold up-regulated, respectively (Fig. 3A-H). Rofecoxib treatment, which had no effect on the incidence of primary islet nonfunction but did prolong the mean graft survival time in autoimmune diabetic NOD mice, resulted in clearly reduced intra-graft iNOS and COX-2, while TGF- $\beta$ expression was increased compared to controls (Fig. 3C,E,F). Rofecoxib-treated mice also expressed lower chemokine messages, relative to control grafts. TGF- $\beta$ treatment, also improving the mean survival time without clear reduction in PNF, had minimal effect on cytokine or chemokine expression with only a lowering of TNF- $\alpha$ expression (Fig. 3B). The most effective group in avoiding early islet graft loss (IL-1ra, pump, $100 \mathrm{mg} / \mathrm{kg} /$ day) showed a dramatic decrease in IL- 1 transcripts and a strong increase in TGF- $\beta$ expression (Fig. 3A,E). Expression of the chemokine MIP-3 $\alpha$ was also reduced, while MCP-1 expression was un-

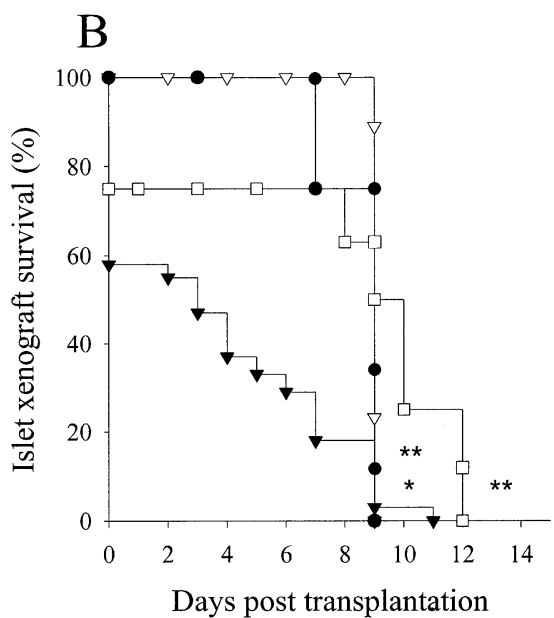

changed (Fig. 3G,H). IP-10 transcripts between different groups showed no changes in respect to controls.

Since NF- $\kappa B$ regulates the expression of pro-inflammatory cytokines, enzymes and chemokines, we examined the expression of p105 (the precursor of the p50 component of NF- $\kappa B$ ) in the islet grafts $8 \mathrm{~h}$ posttransplantation. No differences in mRNA expression for $N F-\kappa B$ could be observed for islets from mice treated with recombinant TGF- $\beta$, while other treatment groups inhibited the NF- $\mathrm{KB}$ expression (Fig. 3I).

Nitrite production in rat islet-grafted autoimmune diabetic NOD mice under anti-inflammatory treatments. We first observed that primary islet non-function was associated with high nitrite plasma concentration $8 \mathrm{~h}$ post-transplantation in spontaneously diabetic autoimmune recipients compared to pre-transplantation values (172.2 \pm 69.8 vs. $37.7 \pm 33.1 \mu \mathrm{mol} / 1, p<0.0001$ ) (Fig. 4).

Nitrite plasma values were efficiently decreased in acetylsalicylic acid and rofecoxib treatment groups in autoimmune diabetic NOD mice to $54 \%$ and $21 \%$ of post-transplant control values, respectively $(p<0.001$ and $p<0.05$, respectively) (Fig. 4). Also IL-1 receptor antagonist, delivered in vivo by osmotic pump, was able to reduce nitrite concentration to pre-transplant control concentration $(45.2 \pm 71.6 \mu \mathrm{mol} / 1, p<0.001)$. Further, increased nitrite values were seen with TGF$\beta$, even above those of the post-transplant control mice (260.0 $\pm 40.7 \mu \mathrm{mol} / 1, p<0.05)$ (Fig. 4).

\section{Discussion}

Recently, enthusiasm for islet cell transplantation as a means of curing Type 1 diabetes received a new boost by the success of the Edmonton group [3,4]. Still, the important advance does not change the fact that islet cells from human origin are needed in high numbers for islet cell replacement, which strongly impedes the progress of the technique in the clinical practice.

Using xenogeneic donor pancreases to increase the donor pool could be a future option. Specific prob- 

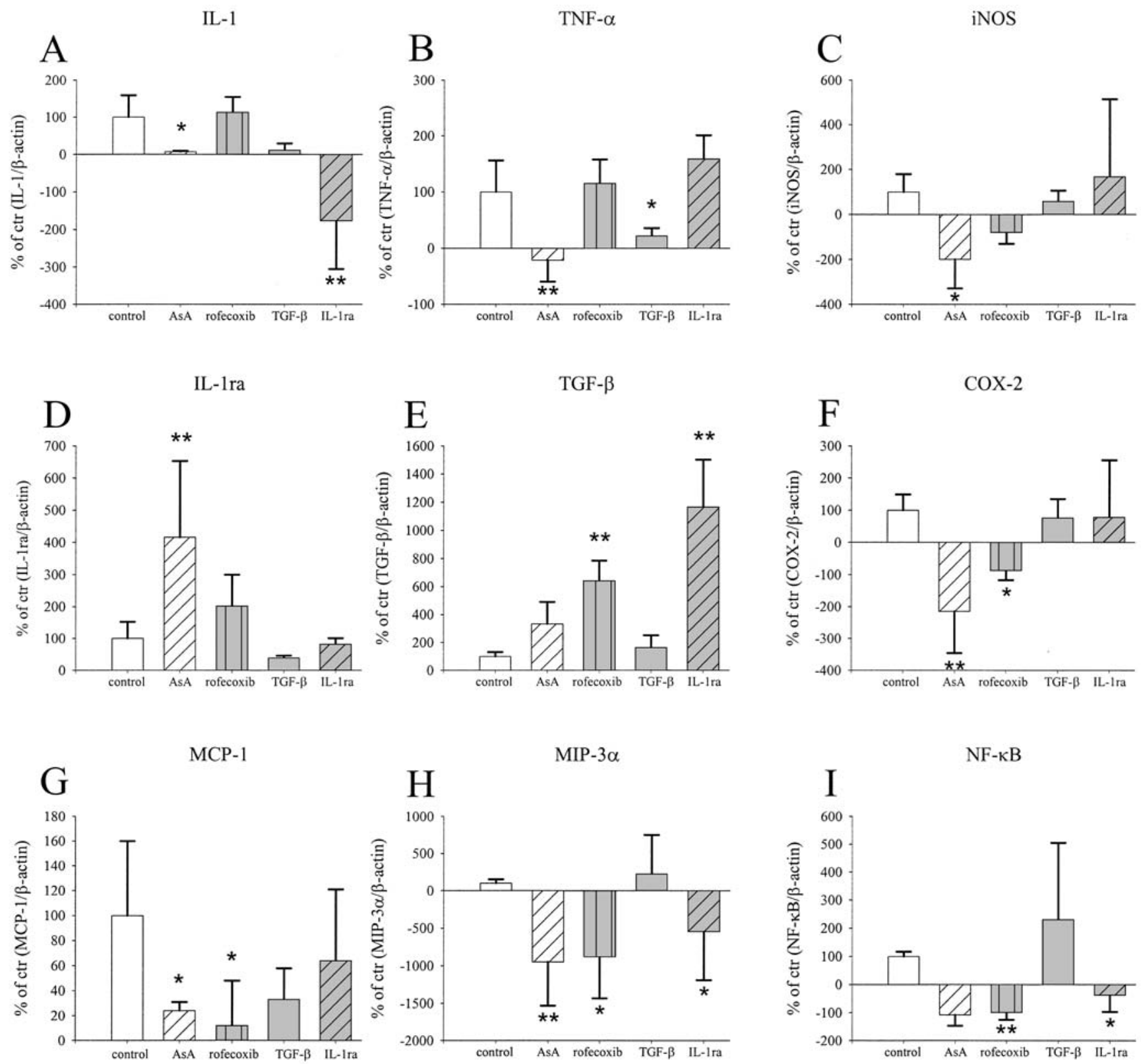

Fig. 3A-I. Expression of inflammation-related molecule-IL1 (A), TNF- $\alpha$ (B), iNOS (C), IL-1 ra (D), TGF- $\beta$ (E), COX-2 (F), MCP-1 (G), MIP-3 $\alpha(\mathbf{H})$ and NF- $\kappa \mathrm{B}(\mathbf{I})-\mathrm{mRNA}$ in rat islet grafts $8 \mathrm{~h}$ post-transplantation. mRNA expression was measured by real-time RT-PCR, with the use of gene-specific oligonucleotide primers and fluorogenic probes. $* p<0.05$, $* * p<0.01$ compared to expression in islet grafts of control mice. Note that IL-1ra treatment was administered by osmotic pump

lems arise, however, when xenogeneic islets are transplanted in animal models of autoimmune diabetes. In this respect, we previously showed that xenogeneic islets transplanted in autoimmune diabetic recipients (the NOD mouse) are extremely vulnerable to immediate graft loss [11]. This early graft loss is most probably due to high inflammation levels locally in the is-

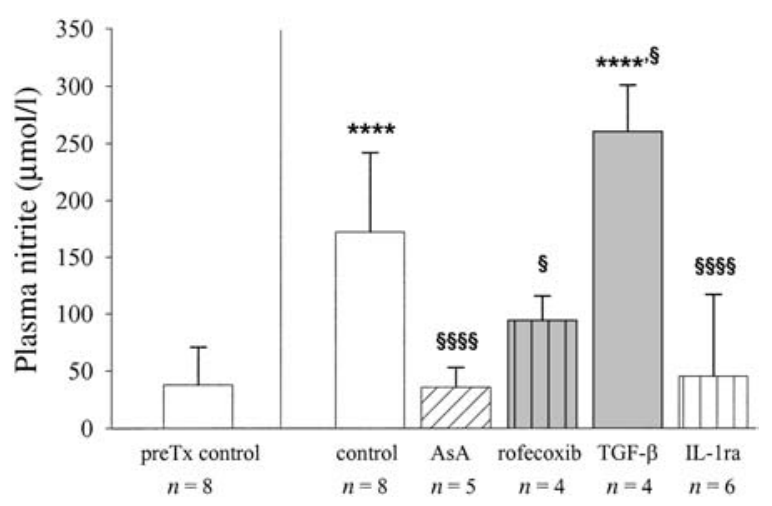

Fig. 4. Plasma nitrite concentration in different treatment regimens in autoimmune diabetic NOD mice before and $8 \mathrm{~h}$ after transplantation in control and treatment groups. $* * * * p<0.001$ compared to pre-transplant (preTx) control values. ${ }^{\S} p<0.05$, $\S \S \S p<0.001$ compared to post-transplant control values. Note that IL-1ra treatment was administered by osmotic pump 
let grafts immediately after transplantation, as suggested by the typical cytokine profile.

Transplantation trauma is suggested to lead to some degree of organ injury and cell death, most often related to an acute storm of many macrophage-derived cytokines, reactive oxygen and nitrogen intermediates. All of these products have the potential of further damaging the grafted islet cells [24, 25, 26]. Additionally, autoimmune-prone diabetic mice are reported to have intrinsic defects in their macrophages, such as anomalies in cell maturation, antigen presentation, antigen processing and accessory cell function [14, 27]. In addition, a dysregulation in the pattern of cytokine production by macrophages is a common feature found in pre-disease NOD mice and is believed to create an appropriate milieu for the start of cell damage and autoimmunity $[12,28]$.

Conventional immunosuppressive regimens, which are often based on the use of calcineurin inhibitors, are mainly T-lymphocyte-driven and are poor macrophage modulators [17]. Unfortunately, also a variety of adverse effects involving the immune system have been documented in both experimental animal models and in the clinical practice [29].

In view of the potentially important role of nonsteroidal anti-inflammatory agents in mediating inhibition of pro-inflammatory cytokine and chemokine secretion and given the acute reactant inflammatory nature of primary islet non-function, we examined whether acetylsalicylic acid, a COX-2 inhibitor (rofecoxib) and specific cytokine inhibitors, including cytokines that act against other cytokines (TGF- $\beta$ ) and antagonists (IL-1ra), would reduce the incidence of initial graft loss in autoimmune diabetic NOD recipients after rat islet cell transplantation.

Acetylsalicylic acid and aspirin-like drugs are nonsteroidal anti-inflammatory agents that reduce inflammation, combat fever and alleviate pain. Here we show that acetylsalicylic acid treatment increased immediate as well as late xenograft function in autoimmune NOD mice. Acetylsalicylic acid is believed to work, in part, by non-selective inhibition of the enzymatic action of COX, also known as prostaglandin endoperoxidase synthase (PGS) [30]. There are two isoforms of COX in vertebrates: COX-1, constitutively expressed in most cells and carrying normal physiological production of PGs, and COX-2, inducibly expressed by cytokine and mitogenic stimuli in inflammatory cells, such as macrophages and neutrophils. It is COX-2 that is associated with inflammation. We observed a down-regulation of IL-1, TNF- $\alpha$, iNOS, COX-2 and chemokine (MCP-1 and MIP-3 $\alpha$ ) transcription and nitrite production by acetylsalicylic acid treatment. It is already known that acetylsalicylic acid inhibits transcription of several cytokines and chemokines and scavenge free radicals by preventing IKB phosphorylation and degradation [31, 32, 33, 34]. It is important to note that the doses of acetylsalicylic acid needed to inhibit inflammation are 10- to 1000-fold higher than those required for PG synthesis inhibition $[35,36]$, implying alternative COX- and PG-independent mechanisms of action. In our model, acetylsalicylic acid administration reduced NF- $\kappa$ Bp105 expression in the islet grafts, suggesting an important role for NF- $\mathrm{NB}$. The main stimuli for chemokine production are early pro-inflammatory cytokines, such as IL- 1 and TNF- $\alpha$, bacterial products, such as LPS, and viral infection. We hypothesize that a dramatic increase in the secretion of chemokines during inflammation (e.g. due to the manipulation during transplantation) can result in the selective recruitment of leukocytes into inflamed tissue, leading to enhanced tissue destruction. We previously reported that chemokines-such as MCP-1, IP-10 and MIP-3 $\alpha$ - can be expressed and secreted by islets during insulitis and islet grafts in NOD mice [23, 37]. On the other hand, acetylsalicylic acid induced up-regulated messages for anti-inflammatory products such as TGF- $\beta$ and IL-1ra, which both are known to possess anti-inflammatory properties.

Traumatic injury, as in the early transplant period, may increase COX-2 expression and cause immune activation, which can provoke cellular damage. In this respect, COX-2 represents a potential pharmacological target to prevent or reverse trauma-induced graft loss. In our study, rofecoxib (Vioxx) - a selective COX-2 inhibitor also known as "super-aspirin"-was unable to reduce the high rate of primary non-function of xenogeneic islets, but did prolong the mean graft survival time in autoimmune diabetic NOD mice. The mechanism of action of rofecoxib is believed to be due to inhibition of PG synthesis, via inhibition of COX-2 [38, 39]. Although intra-graft enzymatic and chemokine gene expression was altered and systemic nitrite production $8 \mathrm{~h}$ post-transplantation was reduced, rofecoxib did not affect, in contrast to acetylsalicylic acid, pro-inflammatory gene expression locally in the islet grafts which might explain the ineffectiveness of rofecoxib to inhibit early islet graft loss. This difference in effect between acetylsalicylic acid and rofecoxib therefore suggests again that the action spectrum of acetylsalicylic acid is much broader than simple COX-2 blockade and that these additional effects are crucial for inhibition of primary islet nonfunction.

TGF- $\beta$ is a member of a gene super-family involved in the regulation of cell growth and differentiation, tissue repair, fibrosis and inflammatory responses [40]. In previous work we found a correlation between low TGF- $\beta$ levels in the graft and primary islet non-function [11]. Here, we show that systemic application of recombinant TGF- $\beta 1$ does not reduce early islet graft loss although does improve the mean survival time. This lack of effect might be due to a failure to reach sufficiently high levels of the cytokine locally in the graft or to insufficient duration of treatment. 
Moreover, when looking at molecular targets, we only observed a down-regulation of TNF- $\alpha$ mRNA expression in the islets, while other cytokine, enzyme and chemokine genes were not affected. Although TGF- $\beta$ is a potent regulator of several macrophage functions including NO production, we observed enhanced nitrite levels in our transplantation model. In agreement with our observations, one study reported that pretreatment with TGF- $\beta 1$ enhanced NO production by macrophages in response to inflammatory stimuli [41]. This effect could again contribute to the absence of protection against primary islet non-function.

IL-1 is a potential target of therapeutic intervention in inflammatory disorders. Indeed, administration of cDNA encoding IL-1ra has the potential of protecting against various forms of arthritis and autoimmune diabetes [42]. The mechanism of action of L-1ra is mainly by blocking the action of IL-1, which is known to trigger induction of iNOS resulting in NO production [43]. Also, local suppression of IL-1 itself by reduction of inflammation has been shown [44, 45]. Induction of iNOS but also COX-2 in macrophages, endothelial cells, and insulin-secreting cells has been shown by IL1 [46]. Here we show that IL-1ra (Anakinra) treatment was even more effective than acetylsalicylic acid in reducing initial islet graft loss, suggesting a pivotal role for IL-1 in the pathogenesis of this early destructive process. IL-1ra reduced not only IL-1, and even more efficiently than acetylsalicylic acid, but also inhibited MIP-3 $\alpha$ expression and nitrite production. Moreover IL-1ra increased the expression of intra-graft TGF- $\beta$ which is known to be a deactivator of macrophage-related cytokine production. However, iNOS and COX-2 levels were not affected by treatment with IL-1ra. In this regard it is known that other signals besides IL-1 for example LPS and extracellular ligands such as TNF- $\alpha$, IFN- $\gamma$ and epidermal growth factor regulate iNOS and COX-2 expression $[47,48]$. The superior action of acetylsalicylic acid on the suppression of iNOS and COX-2 in our model could be a direct consequence of the broader action of this compound compared to the very specific action of IL-1ra.

Taken together, these observations made in the different treatment groups suggest that indeed inflammation is important in causing early islet graft failure. By blocking this inflammation critical islet damage can be avoided. This damage might be extremely severe causing primary islet non-function or could in some cases be more subtle causing sub-lethal islet damage, rendering the islets more susceptible to subsequent destruction mechanisms. This is suggested by the fact that all treatments could delay the destruction of islets compared to control mice. In contrast, no survival past 11 days was observed, suggesting that at one point the T-lymphocyte-driven immune system most probably takes over, eventually destroying all grafts. Introducing anti-inflammatory agents in the process of clinical islet transplantation in order to avoid acute islet loss due to peri-transplant inflammation might be an important key in maximizing success. This effect can also be exploited in the context of allogeneic islet transplantation, as we have shown previously that (although less frequent) primary islet non-function also occurs in allogeneic islet transplantation in the context of autoimmune diabetes [11]. Of interest is the finding that the Edmonton group treated their successfully transplanted patients with low-dose acetylsalicylic acid in the pre-transplantation period [3]. Although in our model no side effects of any treatment were observed, in humans acetylsalicylic acid and other nonsteroidal anti-inflammatory drugs are notorious for their unwanted side effects, including gastro-duodenal ulcers and excessive bleeding. Therefore, the more specific agents, such as IL-1ra, might be a better therapeutic option.

In conclusion, our study shows that anti-inflammatory agents, especially acetylsalicylic acid and IL-1 receptor antagonist have great potential in inhibition of primary non-function after xenogeneic islet transplantation in the context of autoimmune diabetic NOD mice. Very high pro-inflammatory and low anti-inflammatory gene expression and high nitrite production $8 \mathrm{~h}$ post-transplantation are important risk factors for graft outcome. Correcting the balance between pro- and anti-inflammation could hold promise for clinical practice in patients.

Acknowledgements. The excellent technical assistance of D. Valckx and J. Laureys is gratefully acknowledged. This work was conducted in collaboration with and supported by the JDRF Center for Prevention of Beta Cell Destruction in Europe under grant number 4-2002-457. Additional grants of the Government of Flanders (GOA/99/10), the Belgium National Ministry of Science (IUAP P5/17), the Flemish Research Foundation (Fonds Voor Wetenschappelijk Onderzoek (FWO) G.0084.02 and a clinical fellowship for C. Mathieu) and the Onderzoeksraad-KUL (a postdoctoral fellowship (PDM/ 02/192) for C. Gysemans) funded this research project. This work was presented, in part, at the Annual Meeting of the European Association for the Study of Diabetes, Budapest, 2002.

\section{References}

1. Bretzel RG, Hering BJ, Federlin KF (1995) Islet cell transplantation in diabetes mellitus-from bench to bedside. Exp Clin Endocrinol Diabetes 103 [Suppl 2]:143-159

2. Samuel T, Cockwell P (2002) Islet cell transplantation. J R Soc Med 95 1:31-33

3. Shapiro AM, Lakey JR, Ryan EA et al. (2000) Islet transplantation in seven patients with type 1 diabetes mellitus using a glucocorticoid-free immunosuppressive regimen. $\mathrm{N}$ Engl J Med 343:230-238

4. Ryan EA, Lakey JR, Rajotte RV et al. (2001) Clinical outcomes and insulin secretion after islet transplantation with the Edmonton protocol. Diabetes 50:710-719

5. Pipeleers D, Keymeulen B, Chatenoud L et al. (2002) A view on beta cell transplantation in diabetes. Ann NY Acad Sci 958:69-76 
6. Kendall WF Jr, Collins BH, Opara EC (2001) Islet cell transplantation for the treatment of diabetes mellitus. Expert Opin Biol Ther 1:109-119

7. Wallgren AC, Karlsson-Parra A, Korsgren O (1995) The main infiltrating cell in xenograft rejection is a CD4+ macrophage and not a T lymphocyte. Transplantation 60:594-601

8. Yi S, Feng X, Hawthorne WJ, Patel AT, Walters SN, O'Connell PJ (2002) CD4+ T cells initiate pancreatic islet xenograft rejection via an interferon-gamma-dependent recruitment of macrophages and natural killer cells. Transplantation 73:437-446

9. Brauker J, Martinson LA, Young SK, Johnson RC (1996) Local inflammatory response around diffusion chambers containing xenografts. Nonspecific destruction of tissues and decreased local vascularization. Transplantation 61:1671-1677

10. Deng S, Ketchum RJ, Kucher T, Weber M, Naji A, Brayman KL (1997) Primary non-function of islet xenografts in rat recipients results from non-T-cell mediated immune responses. Transplant Proc 29:1726-1727

11. Gysemans CA, Waer M, Valckx D et al. (2000) Early graft failure of xenogenic islets in NOD mice is accompanied by high levels of IL- 1 and low levels of TGF- $\beta$ mRNA in the grafts. Diabetes 49:1992-1997

12. Alleva DG, Pavlovich RP, Grant C, Kaser SB, Beller DI (2000) Aberrant macrophage cytokine production is a conserved feature among autoimmune-prone mouse strains. Elevated interleukin (IL)-12 and an imbalance in tumor necrosis factor- $\alpha$ and IL-10 define a unique cytokine profile in macrophages from young NOD mice. Diabetes 49:1106-1115

13. Charre S, Rosmalen JG, Pelegri C et al. (2002) Abnormalities in dendritic cell and macrophage accumulation in the pancreas of nonobese diabetic (NOD) mice during the early neonatal period. Histol Histopathol 17:393-401

14. O'Brien BA, Huang Y, Geng X, Dutz JP, Finegood DT (2002) Phagocytosis of apoptotic cells by macrophages from NOD mice is reduced. Diabetes 51:2481-2488

15. Jansen A, Hagen M van, Drexhage HA (1995) Defective maturation and function of antigen-presenting cells in type 1 diabetes. Lancet 345:491-492

16. Plesner A, Greenbaum CJ, Gaur LK, Ernst RK, Lernmark A (2002) Macrophages from high-risk HLA-DQB $1 * 0201 /$ *0302 type 1 diabetes mellitus patients are hypersensitive to lipopolysaccharide stimulation. Scand J Immunol 56: 522-529

17. Vial T, Choquet-Kastylevsky G, Descotes J (2002) Adverse effects of immunotherapeutics involving the immune system. Toxicology 174:3-11

18. Gysemans C, Waer M, Laureys J, Bouillon R, Mathieu C (2001) A combination of KH1060, a vitamin D(3) analogue, and cyclosporin prevents early graft failure and prolongs graft survival of xenogeneic islets in nonobese diabetic mice. Transplant Proc 33:2365

19. Gysemans C, Waer M, Laureys J, Bouillon R, Mathieu C (2001) Leflunomide and its analogue X920715 synergize with cyclosporin A in preventing early graft failure and delaying graft rejection of xenogeneic islets in nonobese diabetic mice. Transplant Proc 33:2094-2095

20. Pozzilli P, Signore A, Williams AJ, Beales PE (1993) NOD mouse colonies around the world: recent facts and figures. Immunol Today 14:193-196

21. Overbergh L, Valckx D, Waer M, Mathieu C (1999) Quantification of murine cytokine mRNAs using real time quantitative reverse transcriptase PCR. Cytokine 11:305-312

22. Giulietti A, Overbergh L, Valckx D, Decallonne B, Bouillon R, Mathieu C (2001) An overview of real-time quantitative PCR: applications to quantify cytokine gene expression. Methods 25:386-401
23. Cardozo AK, Proost P, Gysemans C, Chen MC, Mathieu C, Eizirik D (2002) IL-1 $\beta$ and IFN- $\gamma$ induce the expression of diverse chemokines and IL-15 in human and rat pancreatic islet cells, and in islets from pre-diabetic NOD mice. Diabetologia 46:255-266

24. Falcon M, Sarvetnick N (1999) The effect of local production of cytokines in the pathogenesis of insulin-dependent diabetes mellitus. Clin Immunol 90:2-9

25. Mathis D, Vence L, Benoist C (2001) $\beta$-cell death during progression to diabetes. Nature 414:792-798

26. Eizirik DL, Mandrup-Poulsen T (2001) A choice of death-the signal-transduction of immune-mediated betacell apoptosis. Diabetologia 44:2115-2133

27. Serreze DV (1993) Autoimmune diabetes results from genetic defects manifest by antigen presenting cells. FASEB J 7:1092-1096

28. Liu J, Beller D (2002) Aberrant production of IL-12 by macrophages from several autoimmune-prone mouse strains is characterized by intrinsic and unique patterns of NF-kappa B expression and binding to the IL-12 p40 promoter. J Immunol 169:581-586

29. Montori VM, Basu A, Erwin PJ, Velosa JA, Gabriel SE, Kudva YC (2002) Post-transplantation diabetes: a systematic review of the literature. Diabetes Care 25:583-592

30. Vane JR (1971) Inhibition of prostaglandin synthesis as a mechanism of action for aspirin-like drugs. Nat New Biol 231:232-235

31. Gautam SC, Pindolia KR, Noth CJ, Janakiraman N, Xu YX, Chapman RA (1995) Chemokine gene expression in bone marrow stromal cells: down-regulation with sodium salicylate. Blood 86:2541-2550

32. Sakurada S, Kato T, Okamoto T (1996) Induction of cytokines and ICAM-1 by pro-inflammatory cytokines in primary rheumatoid synovial fibroblasts and inhibition by $\mathrm{N}$-acetyl-L-cysteine and aspirin. Int Immunol 8:1483-1493

33. Shackelford RE, Alford PB, Xue Y, Thai SF, Adams DO, Pizzo S (1997) Aspirin inhibits tumor necrosis factor-alpha gene expression in murine tissue macrophages. Mol Pharmacol 52:421-429

34. Shi X, Ding M, Dong Z et al. (1999) Antioxidant properties of aspirin: characterization of the ability of aspirin to inhibit silica-induced lipid peroxidation, DNA damage, NF-kappaB activation, and TNF-alpha production. Mol Cell Biochem 199:93-102

35. Weissmann G (1991) Aspirin. Sci Am 264:84-90

36. Tegeder I, Pfeilschifter J, Geisslinger G (2001) Cyclooxygenase-independent actions of cyclooxygenase inhibitors. FASEB J 15:2057-2072

37. Chen MC, Proost P, Gysemans C, Mathieu C, Eizirik DL (2001) Monocyte chemoattractant protein-1 is expressed in pancreatic islets from prediabetic NOD mice and IL-1 $\beta$ exposed human and rat islet cells. Diabetologia 44:325-332

38. Hillson JL, Furst DE (2000) Rofecoxib. Expert Opin Pharmacother 1:1053-1066

39. Atkinson HG (2002) COX-2 inhibitors: better than traditional NSAIDs? Vioxx and Celebrex may be no less risky than NSAIDs. Health News 8:5

40. Clark DA, Coker R (1998) Transforming growth factor-beta (TGF-beta). Int J Biochem Cell Biol 30:293-298

41. Lin JY, Seguin R, Keller K, Chadee K (1995) Transforming growth factor-beta 1 primes macrophages for enhanced expression of the nitric oxide synthase gene for nitric oxidedependent cytotoxicity against Entamoeba histolytica. Immunology 85:400-407

42. Prud'homme GJ, Lawson BR, Theofilopoulos AN (2001) Anticytokine gene therapy of autoimmune diseases. Expert Opin Biol Ther 1:359-373 
43. Mandrup-Poulsen T (1996) The role of interleukin-1 in the pathogenesis of IDDM. Diabetologia 39:1005-1029

44. Granowitz EV, Vannier E, Poutsiaka DD, Dinarello CA (1992) Effect of interleukin-1 (IL-1) blockade on cytokine synthesis: II. IL-1 receptor antagonist inhibits lipopolysaccharide-induced cytokine synthesis by human monocytes. Blood 79:2364-2369

45. Joosten LA, Helsen MM, van de Loo FA, van den Berg WB (1996) Anti-cytokine treatment of established type II collagen-induced arthritis in DBA/1 mice. A comparative study using anti-TNF alpha, anti-IL-1 alpha/beta, and IL1Ra. Arthritis Rheum 39:797-809
46. Eiririk DL, Flodström M, Karlsen AE, Welsh N (1996) The harmony of the spheres: inducible nitric oxide synthase and related genes in pancreatic beta cells. Diabetologia 39:875-890

47. Hammond RA, Hannon R, Frean SP, Armstrong SJ, Flower RJ, Bryant C (1999) Endotoxin induction of nitric oxide synthase and cyclooxygenase- 2 in equine alveolar macrophages. Am J Vet Res 60:426-431

48. Gallo O, Fabbroni V, Sardi I, Magnelli L, Boddi V, Franchi A (2002) Correlation between nitric oxide and cyclooxygenase-2 pathways in head and neck squamous cell carcinomas. Biochem Biophys Res Commun 299:517-524 